\title{
Effect of arsenite on the proteome of earthworms Eisenia fetida
}

\author{
Yali Wang ${ }^{1,2,3}$, Yinsheng $\mathrm{Li}^{2}{ }^{2,}$, Hongpei Geng ${ }^{1}$, Qian Zuo ${ }^{1}$, Michelle Thunders ${ }^{4}$, Jiangping Qiu ${ }^{2}$ \\ 1 School of Environmental Engineering, Henan University of Technology, Zhengzhou 450001, China \\ 2 School of Agriculture and Biology, Shanghai Jiao Tong University, Shanghai 200240, China \\ 3 State Environmental Protection Key Laboratory of Monitoring for Heavy Metal Pollutants, Changsha 410000, China \\ 4 Department of Pathology and Molecular Medicine, University of Otago, Wellington 6242, New Zealand
}

\section{H I G H L I G H T S}

- 24 differentially expressed proteins (DEPs) were identified by proteomic method.

- DEPs function as metabolism, signal transduction, stress-related and transport etc. - Proteomics of As exposure help to explore its toxicity mechanism in earthworm.

\section{ARTICLE INFO}

\section{Article history:}

Received July 26, 2021

Revised October 19, 2021

Accepted October 23, 2021

Keywords:

Earthworm

$\mathrm{As}^{3+}$

Two dimensional electrophoresis

MALDI-TOF/TOF-MS

Proteomics

\section{G RAPHICAL ABSTRACT}

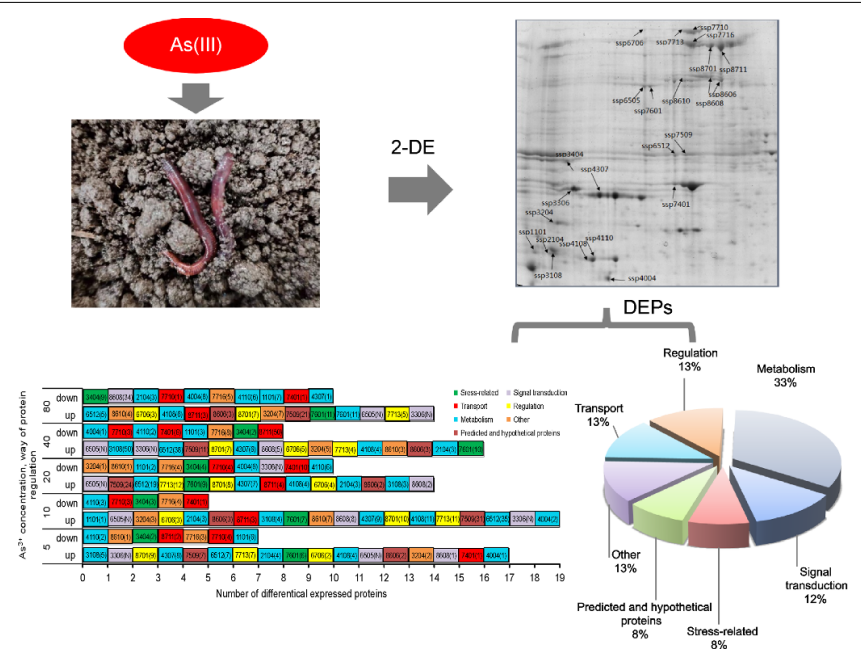

A B STR A C T

Arsenic (As) is broadly distributed due to natural and anthropogenic sources, and it is toxic to organisms. This study aimed to investigate the proteomic response in earthworm exposed to $\mathrm{As}^{3+}$. Earthworms were exposed to $\mathrm{As}^{3+}$ in soil at $5-80 \mathrm{mg} \mathrm{kg}^{-1}$, and samples were collected after 60 days exposure. Two-dimensional electrophoresis (2-DE) was used to separate the proteins in earthworm homogenate, then differentially expressed proteins (DEPs) were identified using MALDI-TOF/TOFMS analysis. After 2-DE, 36 DEPs were found and 24 of them were successfully identified. $79.2 \%$ of DEPs were upregulated compared to the control group. The maximum fold change reached 53.8 in spot 3108 in the $80 \mathrm{mg} \mathrm{kg}^{-1}$ As group. Two proteins were not found in the control group but found in the As treated groups. Proteins were grouped into metabolism, signal transduction, stress-related, transport, regulation, and predicted/hypothetical protein categories based on their function. The protein-protein interaction between the DEPs indicated that serum albumin (ALB) is very important, related to 6 other proteins. Proteins were then verified by western blot, the results were in agreement with the proteomic analyses. The identification of induced or repressed proteins because of $\mathrm{As}^{3+}$ in earthworms is helpful to explore the underlying mechanisms of soil arsenic ecotoxicity.

(c) Higher Education Press 2021

* Corresponding author

E-mail address: yinshengli@sjtu.edu.cn (Y. Li) 


\section{Introduction}

Arsenic (As), a metalloid element, is widely distributed in the soil environment and As contamination is commonplace (Kwon et al., 2012). As contamination in soil may cause toxicity in plants and animals (Pendergrass and Butcher, 2006; Wang et al., 2018; Tang et al., 2020). Arsenic content in soils varies (3.5-935 mg As $\mathrm{kg} \mathrm{soil}^{-1}$ ) in different reports (Huang et al., 2006; Liu et al., 2010). Sodium arsenite is an important inorganic arsenicals. It is usually a component of in insecticides and preservatives, and is still extensively used in modern industry (Mandal and Suzuki, 2002). Arsenite has high affinity for thiol groups in organisms, thus may cause toxic effects (Oremland and Stolz, 2003).

Earthworms are very important soil fauna, they play an important role in maintaining soul fertility. Earthworms can also take in the soil pollutants via their skin and alimentary canal, and thus they are recognized as indicators of soil ecosystem (Gong and Perkins, 2016). The physiological and biochemical changes in earthworm body can indirectly reflect the environmental change and now several earthworms have been suggested as sentinels to monitor the terrestrial ecosystem (Sauve et al., 2002; Ricketts et al., 2004; Li et al., 2016).

Proteomics mainly studies the functional proteins in the cells, tissues or organisms (Wang et al., 2010b; Tang et al., 2020). Using proteomics analysis, we can get direct information of the samples at protein level (Naaby-Hansen et al., 2001). The information obtained provides meaningful and comprehensive results that assist in understanding the impact of a toxin to an organism at a protein level, including how protein interact with one another. These interactions will provide more information than genomic/transcriptomic studies (Fanous et al., 2008). The proteomic response to arsenite has been studied in a range of cell types and species, including Klebsiella pneumoniae (Daware et al., 2012), human lung cells (Lau et al., 2004), Litopenaeus vannamei (Ning et al., 2019) and rats (Wu et al., 2018). However, proteomics research in earthworms lags behind other model species (Wang et al., 2010b). There is one previous study investigating the effects of roxarsone on the earthworm (Guo et al., 2015), roxarsone is an organic arsenic, and its toxicity is less than inorganic arsenic. In that study, the author studied only one concentration of the roxarsone, so there is a need to study the toxicity of inorganic arsenic on the earthworm. Data on protein profiling of earthworms following arsenite exposure is still lacking in the research literature. In this study, we use the 2-DE method to analyze the proteomic response in earthworm Eisenia fetida exposed to $\mathrm{As}^{3+}$. The objective was to identify the differentially expressed proteins (DEPs) of the earthworm response to arsenite, then explore the underlying mechanism of arsenite toxicity.

\section{Materials and methods}

\subsection{Reagents, soils and animals}

Sodium arsenite was purchased from Merck KGaA (Germany). All the reagents used for extracting proteins (Trichlor- oacetic acid (TCA), dithiothreitol (DTT), iodoacetamide, acetone) were purchased from Sigma-Aldrich (St Louis, MO, USA). Reagents used for 2-DE (lauryl sodium sulfate (SDS), Immobilized $\mathrm{pH}$ gradient (IPG) strips (17 cm, linear $\mathrm{pH} 4-7$ ) and 2-dimensional electrophoresis buffer (2-DE starter Kit) were purchased from Bio-Rad (Hercules, CA, USA). Primary antibodies of Transferrin Receptor (CD71, BM4886), Cytokeratin 8 (CK8, BM4225), Serum Albumin (BSA, BM4963), Dystrophin (DMD, PB0292), Cingulin (21369-1-AP), HSP 70 (BM4335), $\beta$-actin (BM0627) and corresponding secondary antibodies were all purchased from Boster Biological Technology (Boster Biological Technology Co., Ltd., Wuhan, China). The other reagents were purchased from Sangon Biotech (Shanghai, China). The solution used in this process was same as Lu et al. (2018). The Coomassie brilliant blue staining solution were: $0.12 \%$ dye, $10 \%$ ammonium sulfate, $10 \%$ phosphoric acid, and $20 \%$ methanol. The decoloring solution was the ultrapure water (18 M $2 . \mathrm{cm})$.

The soil used in this study was from farm land in Minhang district, Shanghai. The soil properties were represented in Wang et al. (2018).

Healthy adult earthworms (Eisenia fetida) were used in this experiment. These earthworms (300-500 mg) were purchased from an earthworm farm and kept in the collected soil for two weeks.

\subsection{Arsenite exposure experiments}

$\mathrm{NaAsO}_{2}$ was added to the prepared soil different As concentration (5, 10, 20, 40, $80 \mathrm{mg} \mathrm{As} \mathrm{kg}^{-1}$ dry soil). After aging the soil for one month, the $E$. fetida were added to the different soil group. Each group has 3 replicates. These groups were kept in the dark at $20 \pm 1^{\circ} \mathrm{C}$ for $60 \mathrm{~d}$. The earthworms were sampled on $60 \mathrm{~d}$. The earthworms were depurated at $20 \pm 1^{\circ} \mathrm{C}$ for $2 \mathrm{~d}$. Proteins for 2-DE were extracted from the freshly depurated earthworms. The earthworms used for western blot were frozen in liquid nitrogen and stored at $-80^{\circ} \mathrm{C}$ until used.

\subsection{2-DE electrophoresis}

Proteins were extracted using the trichloroacetic acid-Acetone (TCA-A) procedure (Wu et al., 2013; Lu et al., 2018). IPG strips were rehydrated overnight with $380 \mu \mathrm{L}$ IEF buffer containing an estimated $1.8 \mathrm{mg}$ protein. The process of IEF and strip balance was outlined by Lu et al. (2018). The strips were transferred to $10 \%$ SDS-PAGE gels for vertical electrophoresis using a Bio-Rad gel system with SDS electrophoresis buffer. The electrophoresis conditions were $120 \mathrm{~V}$ for 45 min and then $300 \mathrm{~V}$ for $4 \mathrm{~h}$. Each sample we did at least 3 replicates.

\subsection{Image analysis}

After the 2-DE electrophoresis, the gels were stained by coomassie brilliant blue (G-250) and washed by ultrapure 
water until the background of the gels was clear. Stained gels were scanned and calibrated with a higher resolution scanner (Bio-Rad, USA). Image analysis was carried out using 2-DE Analysis Software (PDQuest ${ }^{\mathrm{TM}}$ Basic- 8.0.1, Bio-Rad, USA). The protein spots were analyzed using the automated software. In this step, we detected and matched the protein spots. The expression of these protein spots was calculated. When the expression of these spots varied more than 2-fold change between untreated group and As treated groups, these protein spots were defined as meaningful protein spots (MPSs). These MPSs were selected for further analysis.

\subsection{Protein identification and database search}

The MPSs were cut from the gels and analyzed by MALDI TOF/TOF TM Analyzer (ABI, Foster City, CA, USA). The specific process and the database search method is as described by Lu et al. (2018). Functional characterization of the identified proteins was conducted using the Gene Ontology Tool (http://www.uniprot.org).

\subsection{Western blot analysis}

To verify whether the identified proteins were truly overexpressed or under expressed in the earthworm, the DEPs with important physiologic function and with major roles in the interaction of the protein network were selected to be measured in earthworm body using western blot. Therefore, transferrin CD71, CK8, BSA, DMD, cingulin and HSP 70 were selected (their functions are described below). The relative fluorescence of CD71, CK8, BSA, DMD, cingulin and HSP 70 compared to $\beta$-actin (expressed as relative fluorescence intensity, RFI) was used to assess relative protein expression level.

\subsection{Quantitative data analysis}

All the protein data were analyzed in SPSS 22.0 (SPSS, Chicago, IL, USA). The protein-protein interaction (PPI) information for DEPs was obtained from the STRING database (http://string-db.org/).

\section{Results and discussion}

3.1 Identification of differentially expressed proteins (DEPs) related to $\mathrm{As}^{3+}$ stress

After 60 days of exposure to different $\mathrm{As}^{3+}$ contaminated soil and control group, the number of the spots detectable on the 2-DE gels was $1279,1001,993,825,1018,1151$, respectively (Fig. 1). In these spots, we found most of them did not have significant changes. 36 MPSs were more than 2-fold difference (either increase or decrease) between the control and the $\mathrm{As}^{3+}$ groups of the earthworms. 26 of them were upregulated and 10 of them were downregulated.

These 36 MPSs were analyzed by mass spectrometry (MALDI-TOF/TOF-MS). 24 of them (DEPs) were successfully identified and matched in the database (Table 1). The results of MALDI-TOF/TOF-MS of spot 7601 is shown in Fig. 2. Because the database (NCBI and SwissProt databases) of the earthworm proteome is limited, only 11 protein spots were identified through matching with earthworm protein sequences.

3.2 Distribution of the differentially expressed proteins in the earthworms exposed to different $\mathrm{As}^{3+}$ concentration

The fold change of 24 DEPs under different $\mathrm{As}^{3+}$ concentration can be seen in Fig. 3. The largest number of upregulated DEPs was found in the $10 \mathrm{mg} \mathrm{kg}^{-1}$ group, followed by the $5 \mathrm{mg} \mathrm{kg}^{-1}$ group. While the largest number of downregulated DEPs was found in the $20 \mathrm{mg} \mathrm{kg}^{-1}$ and $80 \mathrm{mg} \mathrm{kg}^{-1}$ groups. The maximum fold change of the upregulated DEPs was found in the $40 \mathrm{mg} \mathrm{kg}^{-1}$ group and reached 50 -fold change (spot 8711). Two of the DEPs (6505 and 3306) were new occurrences in the $\mathrm{As}^{3+}$ treated groups.

The protein expression of the 24 DEPs on the 2-DE did not present an obvious correlation with the $\mathrm{As}^{3+}$ concentration except for spot 7601 . This spot exhibited a 6 -fold upregulation in the $5 \mathrm{mg} \mathrm{kg}^{-1}$ treatment, extending to 7 -fold in $10 \mathrm{mg} \mathrm{kg}^{-1}$, 9-fold in $20 \mathrm{mg} \mathrm{kg}^{-1}, 10$-fold in $40 \mathrm{mg} \mathrm{kg}^{-1}$ and 11-fold change in the $80 \mathrm{mg} \mathrm{kg}^{-1}$ treatment groups. At 60 days' exposure, two proteins (6505 and 3306) occurred in the added As groups, they were upregulated in the groups with different $\mathrm{As}^{3+}$ concentrations, the two proteins were not expressed in the control group.

DEPs were classified based on their function. There were 7 categories, and the proportion of each group is shown in Fig. 4. These DEPs were analyzed by their number and fold changes, different groups of the DEPs were found to have a similar proportion in the two methods. The largest proportion was classified as metabolism. This is similar to previous studies investigating earthworm response to $\mathrm{Cd}$ and enrofloxacin exposure (Zhang et al., 2017; Lu et al., 2018). The second dominant group was "regulation proteins" and "transport proteins" accounting for $13 \%$ of the all DEPs, followed by "cytoskeletal protein," "stress-related," "signal transduction" and "predicted and hypothetical proteins" respectively. This result is in line with those found in experiments on Staphylococcus sp. \#NIOSBK35 under the arsenite exposure (Shah and Damare, 2018).

\subsection{Functional analysis of different expressed proteins}

\subsubsection{Metabolism}

In the 24 DEPs, 8 DEPs were grouped into the metabolism category (Table 1), accounting for 1/3. Spot 2104 (CELA3B in Fig. 5; same below) was identified as lumbrokinase-5, chymotrypsin-like elastase family, member 3B, efficient protease with alanine specificity but only little elastolytic 

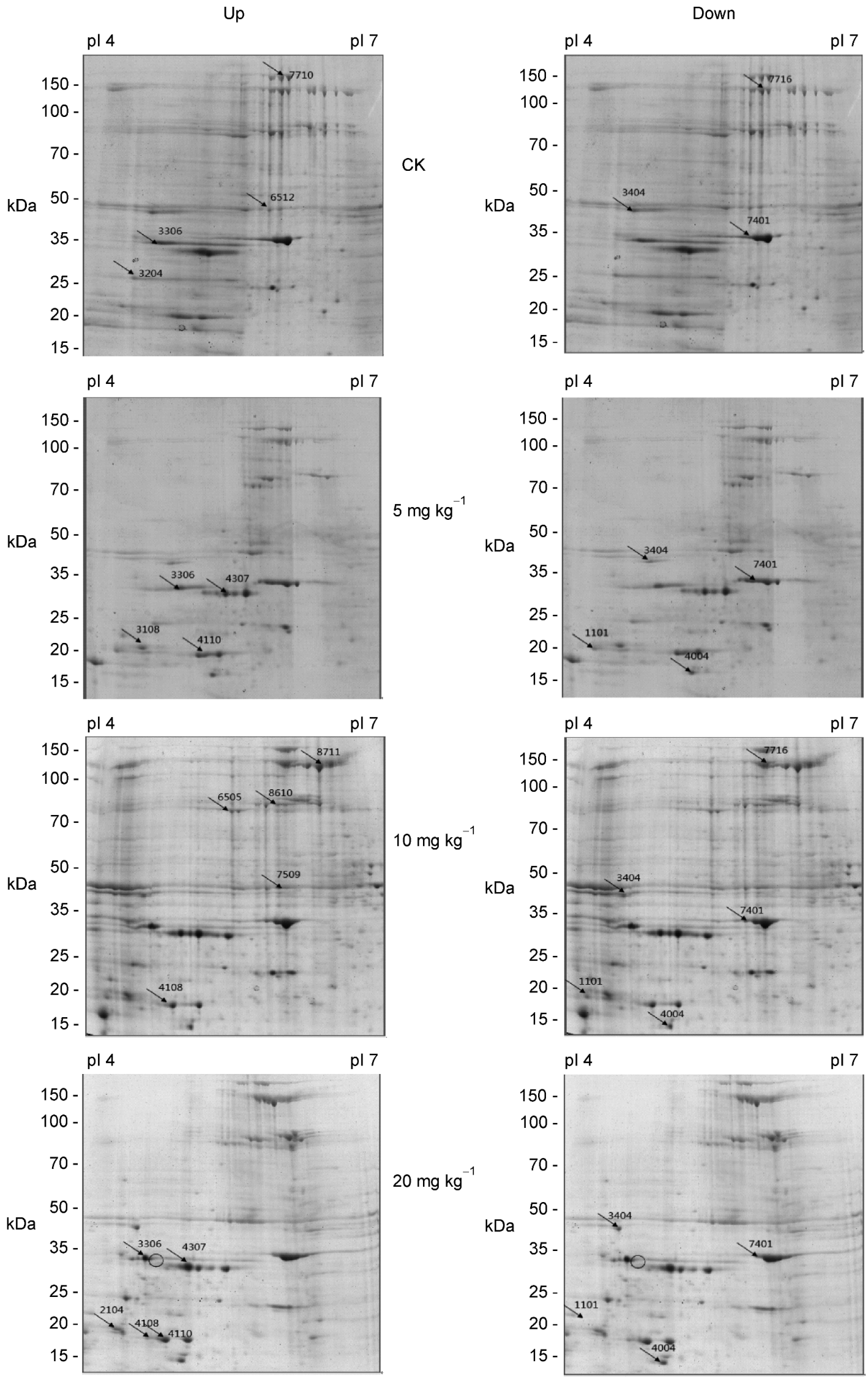

Fig. 1 Two dimensional electrophoresis maps of earthworm proteins extracted from both control and $\mathrm{As}^{3+}$ - treated 5, 10, 20, 40 and $80 \mathrm{mg}$ $\mathrm{kg}^{-1}$ earthworms after 60 day of exposure. Arrows represent significantly $(p<0.05)$ increased and decreased protein abundance. 

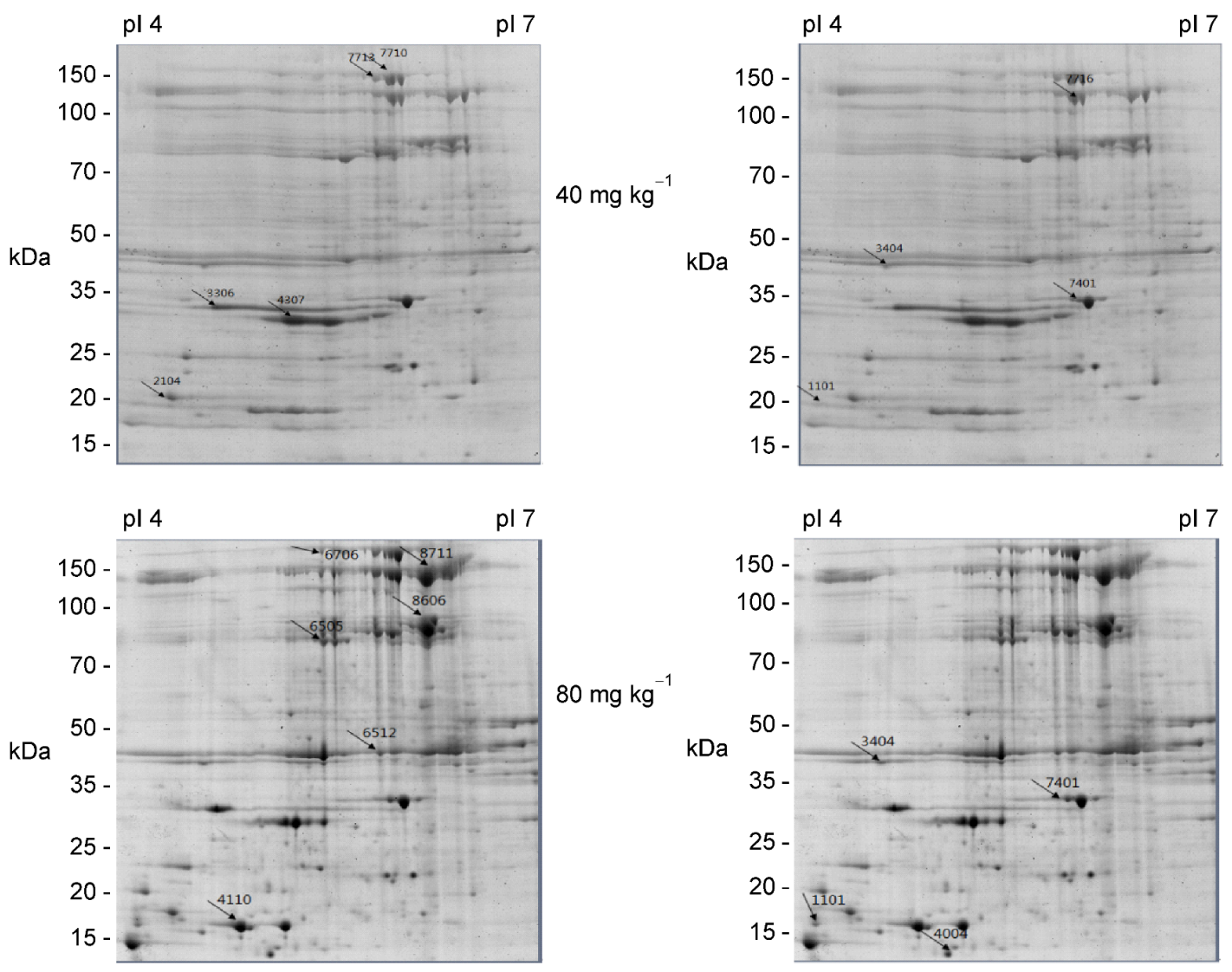

Fig. 1 Continued

activity. Lumbrokinase is an effective enzyme extracted by a method modified from Mihara in 1983 from a Chinese traditional herb (Mihara and Akazawa, 1983; Mihara et al., 1991). In this study, it was associated with only one other spot, CTRL, upregulated in the $5,10,20$ and $40 \mathrm{mg} \mathrm{kg}^{-1}$ As group, but downregulated in the $80 \mathrm{mg} \mathrm{kg}^{-1}$ group. The expression of the spot 2104 reached maximum in the $20 \mathrm{mg} \mathrm{kg}^{-1}$ group, the fold change times reached 3.2. Lumbrokinase has fibrinolytic activity, and it can prevent blood coagulation in earthworms (Ge and Lang, 2003).

The spot 3108 (KLKB1) and 1101 (KLKB1) were identified as a fibrinolytic enzyme. The enzyme cleaves the bonds between Lys-Arg and Arg-Ser. In a reciprocal reaction, the fibrinolytic enzyme can active factor XII. The fibrinolytic enzyme release bradykinin from the HMW kininogen. Bradykinin is very important in the renin-angiotensin system. KLKB1 was first found in Lumbricus rubellus in 1991 (Mihara et al., 1991). The expression of two spots in this study is different, the spot 3108 was upregulated in all the As treated groups, and the maximum fold change reached 53.4 under the $80 \mathrm{mg} \mathrm{kg}^{-1}$ group, the minimum is the $20 \mathrm{mg} \mathrm{kg}^{-1}$ group, where fold change reached 2.5. Conversely, spot 1101 was downregulated in all the As treated groups except the $10 \mathrm{mg} \mathrm{kg}^{-1}$ group. The expression of spot 1101 reached maximum under the $10 \mathrm{mg} \mathrm{kg}^{-1}$ group, but the fold change only reached 1.1 , while the minimum is in the $80 \mathrm{mg} \mathrm{kg}^{-1}$ group, where the fold change reached 7.0 compared to the control group.

Spots 4108 and 4004 (CTRL) was identified as a fibrinolytic protease. 4108 was upregulated in all the As treated group, the maximum was found in the $10 \mathrm{mg} \mathrm{kg}^{-1}$ As treatment, where the fold change reached 10.6 , the minimum one was the $40 \mathrm{mg} \mathrm{kg}^{-1}$ group, where the fold change reached 3.5. The expression of spot 4004 was upregulated in the $5 \mathrm{mg} \mathrm{kg}^{-1}$ group and $10 \mathrm{mg} \mathrm{kg}^{-1}$ group, downregulated in the 20,40 and $80 \mathrm{mg} \mathrm{kg}^{-1}$ groups. The maximum fold change reached 8.4 under the $80 \mathrm{mg} \mathrm{kg}^{-1}$ As treatment. In the PPI (Fig. 5), CTRL was associated with two protein spots (CELA3B and ALB). CTRL is an important chemotherapeutic agent, dissolving blood fibrin clots (Park et al., 1999). The expression of this protease is changed by the environment conditions, such as pressure and temperature (Akazawa et al., 2018). The protein was upregulated under enrofloxacin exposure. These results were in line with those of Lu et al., (2018), whereby the protein was upregulated under enrofloxacin exposure.

Lumbrokinase (spot 4110, TMPRSS9) presents both kinase activity and serine-type endopeptidase activity. Lumbrokinase can prevent blood coagulation in earthworms (Ge and Lang, 2003). In all the $\mathrm{As}^{3+}$ treatments of this experiment, the expression of spot 4110 was all downregulated, the 

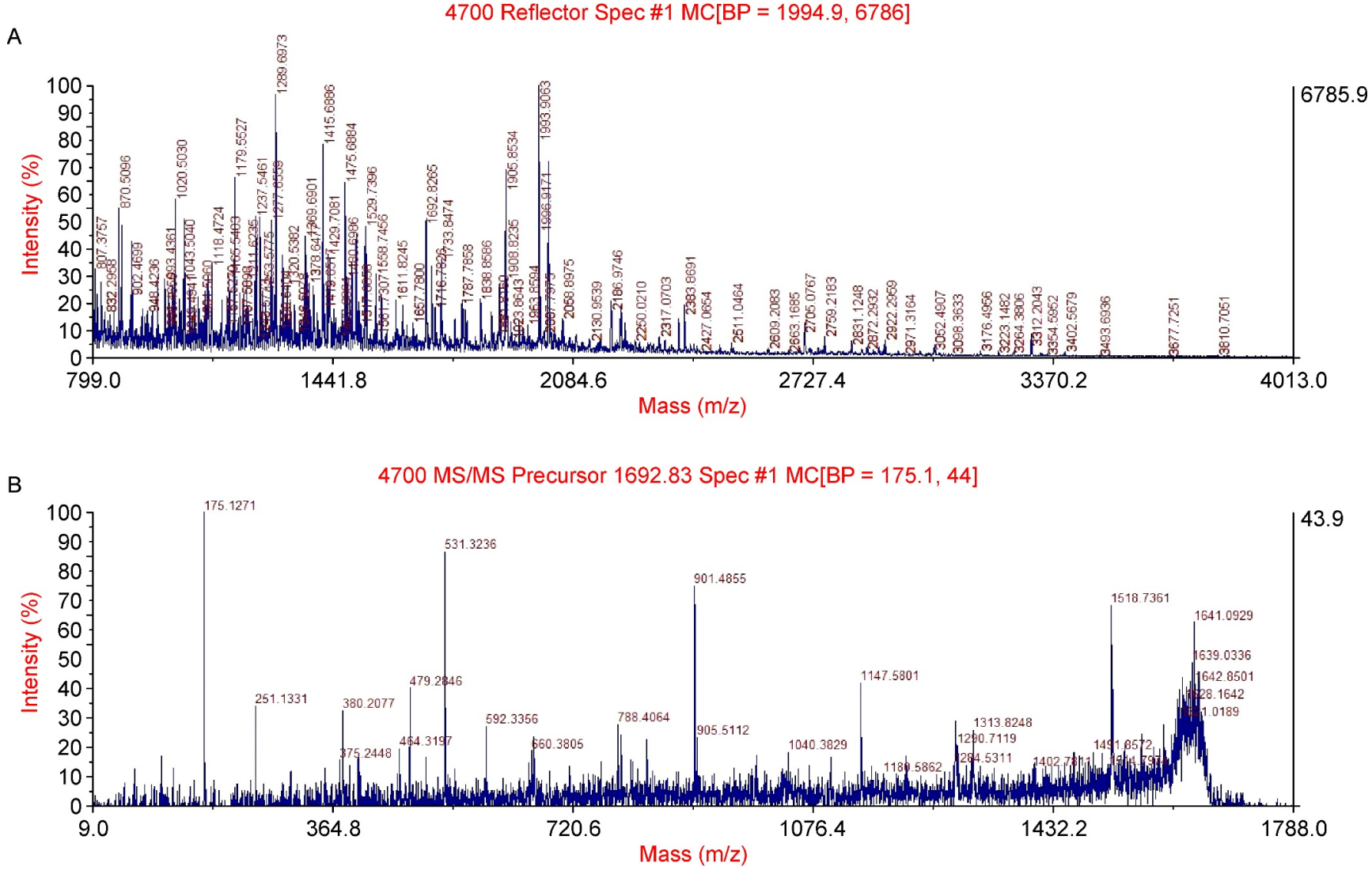

Fig. 2 Identification of spot 7601 via MALDI- TOF/TOF-MS. (A) The MS spectra. (B) MS/MS spectra.

minimum was in the $20 \mathrm{mg} \mathrm{kg}^{-1}$ group, the fold change here reached 5.9. It was free from correlations with other proteins in the PPI (Fig. 5).

Spot 4307 (2GTL_M) was identified as Chain M which is a component of laminin. It has been demonstrated that the laminins are a family of heterotrimeric glycoproteins present specifically in basement membranes. There is no information on this protein in the STRING database. Laminins have many biological activities, such as the promotion of cell adhesion, migration, neurite outgrowth, tumor metastasis and angiogenesis (Katagiri et al., 2014). Laminin-2 (formerly merosin) is composed of $\alpha 2$ chain (formerly $M$ chain), $\alpha 1$ chain homolog, $\beta 1$ and $\gamma 1$ chains. In this study, this protein was upregulated under exposure of all the As-treatments except the $80 \mathrm{mg} \mathrm{kg}^{-1}$ group, suggesting As exposure seriously affects the cell growth of E. fetida. The maximum fold change is in the $10 \mathrm{mg} \mathrm{kg}^{-1}$ group and reached 8.6 .

Actin (spot 6512, ACTG1) is a highly abundant protein in the body. It forms the filaments which make up the cytoskeleton. Actin has an important role in many cellular activities, such as cytoplasmic flow, cell migration, cell division, and muscle contraction (Ciryam et al., 2013; Szewczak-Harris and Löwe, 2017). In the present study, actin was upregulated in all the As treatments, the maximum fold change reaching 38.2. This was similar to the results from another study on $E$. fetida under 2,2', 4,4-tetrabromodiphenyl ether exposure (Ji et al., 2013). The function of actin is like GapA. GapA is also essential for the maintenance of basic cellular functions. GapA was also upregulated under the ciprofloxacin exposure in Escherichia coli (Ye et al., 2016).

\subsubsection{Signal transduction}

Three spots $(6505,8608$ and 3306 , LMNA) were identified as cytoplasmic intermediate filament proteins in Phascolion strombus and intermediate filament gliarin in Hirudo medicinalis, respectively. Spot 6505 and spot 3306 were new expression proteins. Those were no expression under the control group, but under the As treated groups, these proteins were expressed, and these proteins were upregulated under all the As treated groups. Spot 8608 was upregulated in all the As groups except the $80 \mathrm{mg} \mathrm{kg}^{-1}$ group, the maximum fold change reached 8.31 in the $10 \mathrm{mg} \mathrm{kg}^{-1}$ group.

The intermediate filament protein is an important component of the nuclear lamina. The nuclear lamina was in the nucleoplasmic slide of the inner nuclear membrane. The nuclear membrane provides a framework for the nuclear envelope and may also interact with chromatin. This protein plays an important role in nuclear assembly, chromatin organization, nuclear membrane and telomere dynamics. This protein can be found in the Trichinella spiralis adult worm infected by trichinellosis (Yang et al., 2015). 


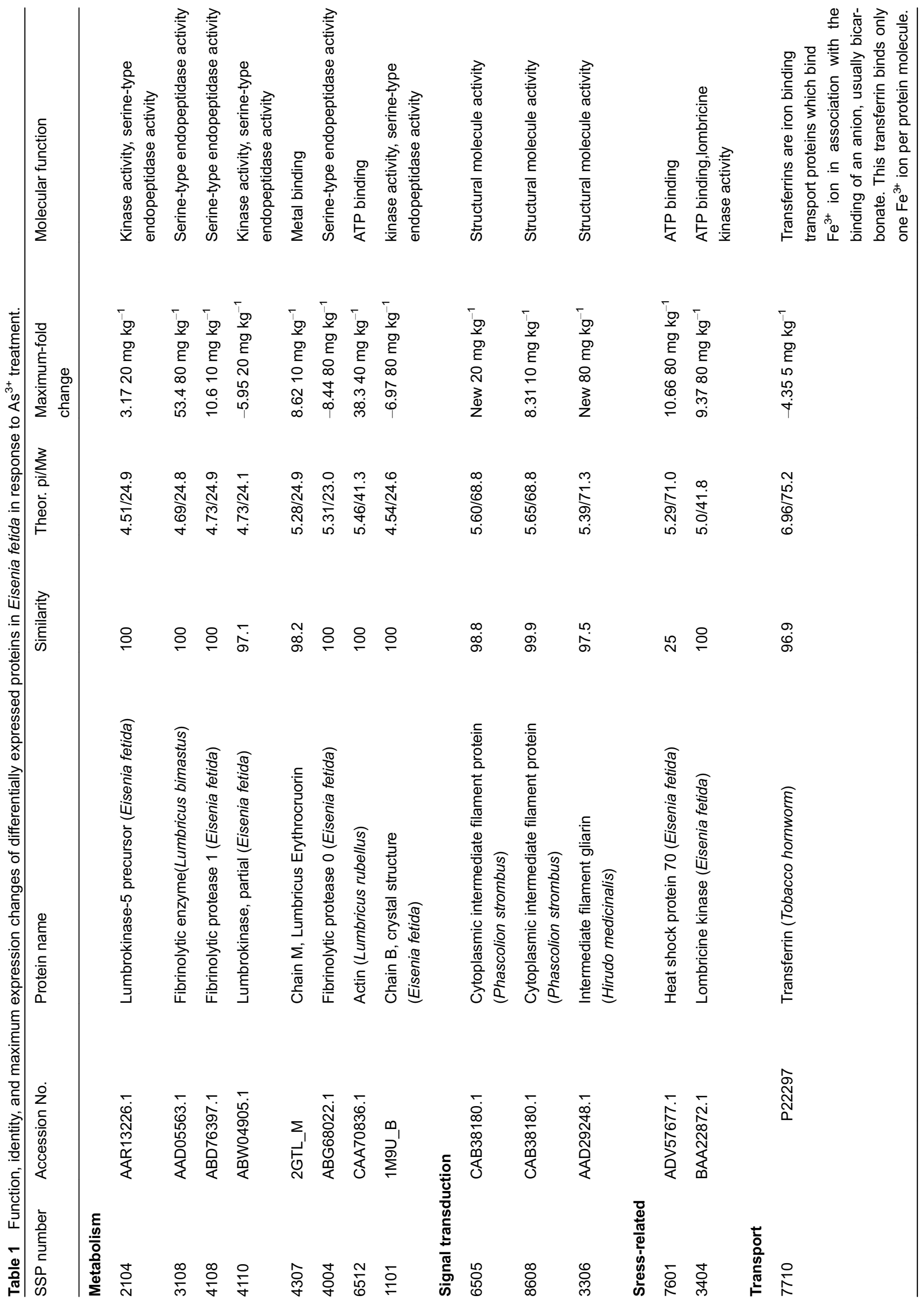



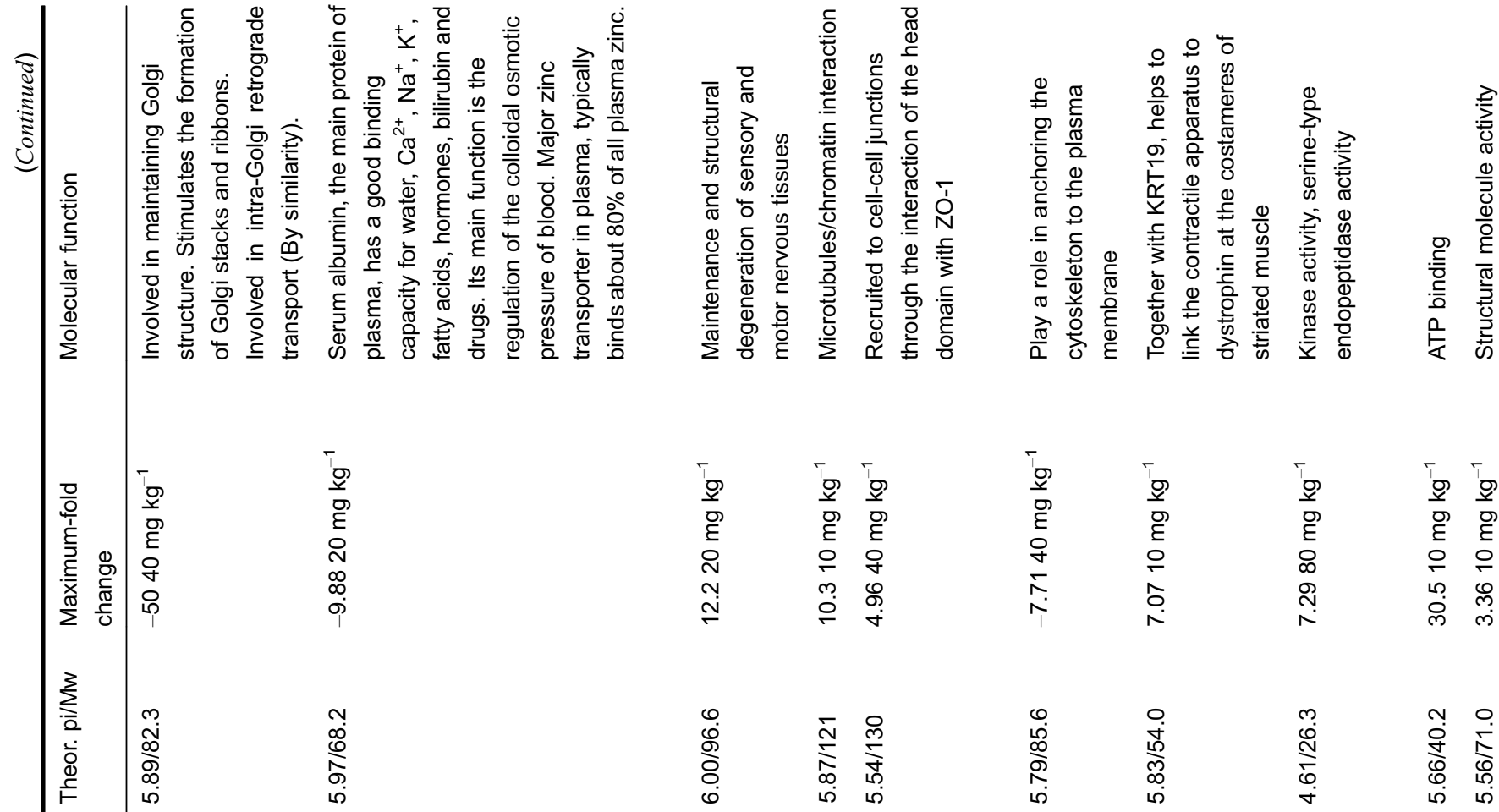

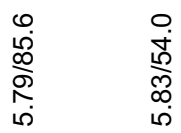

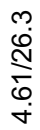

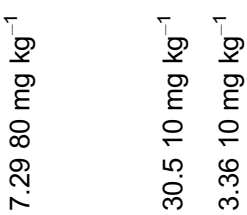

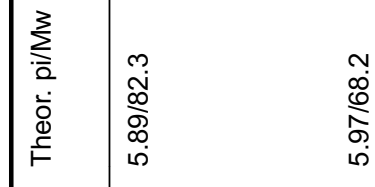

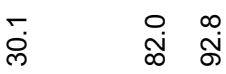

잉

음

응
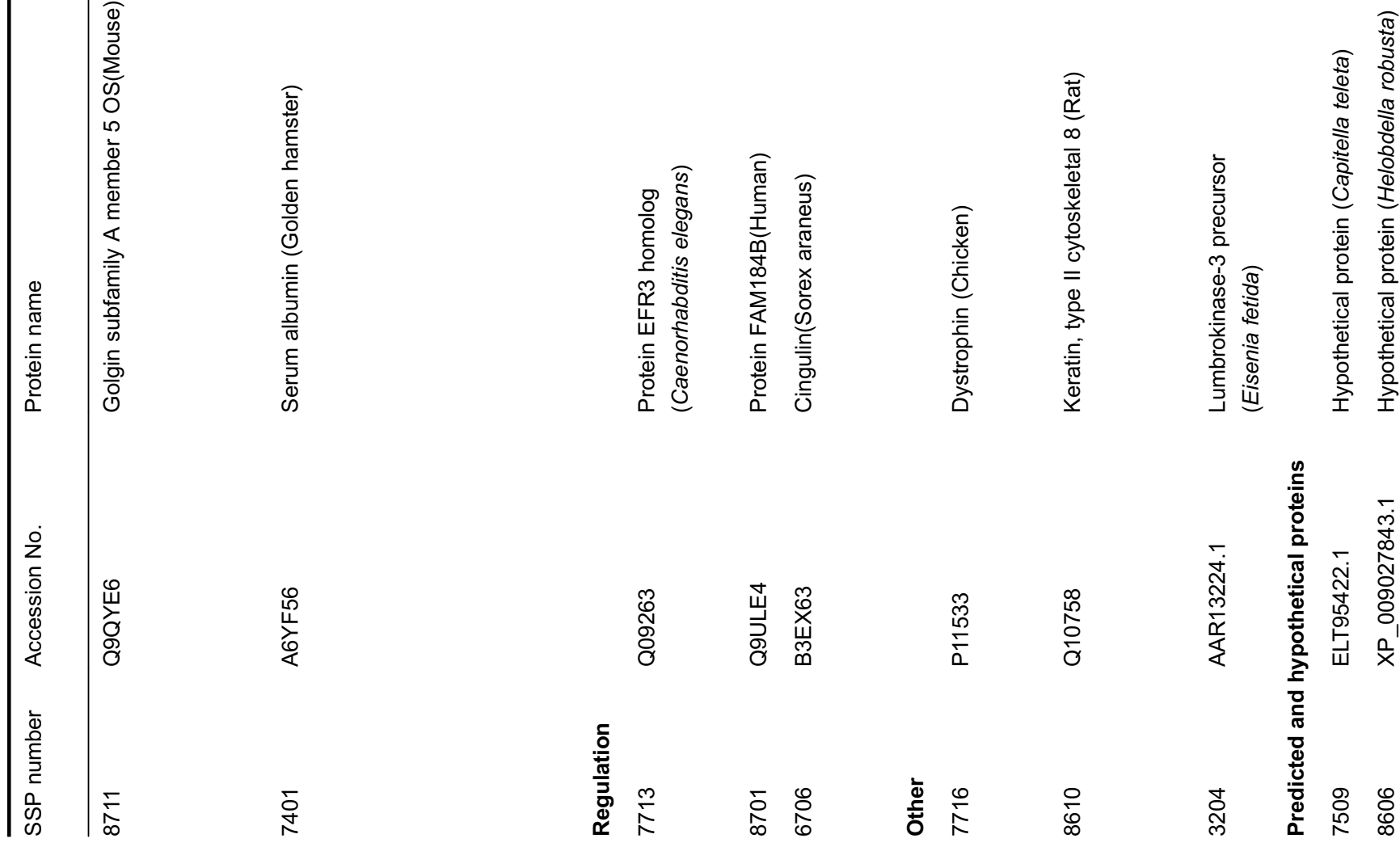

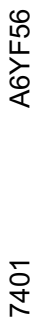

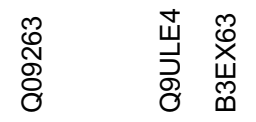

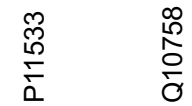

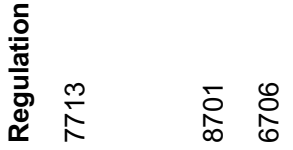

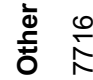

$\stackrel{\circ}{\circ}$

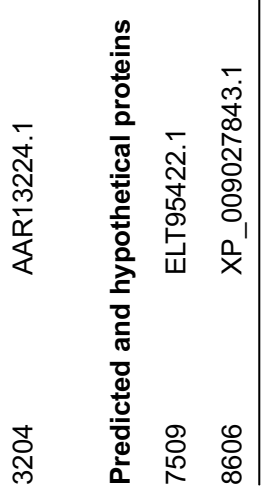




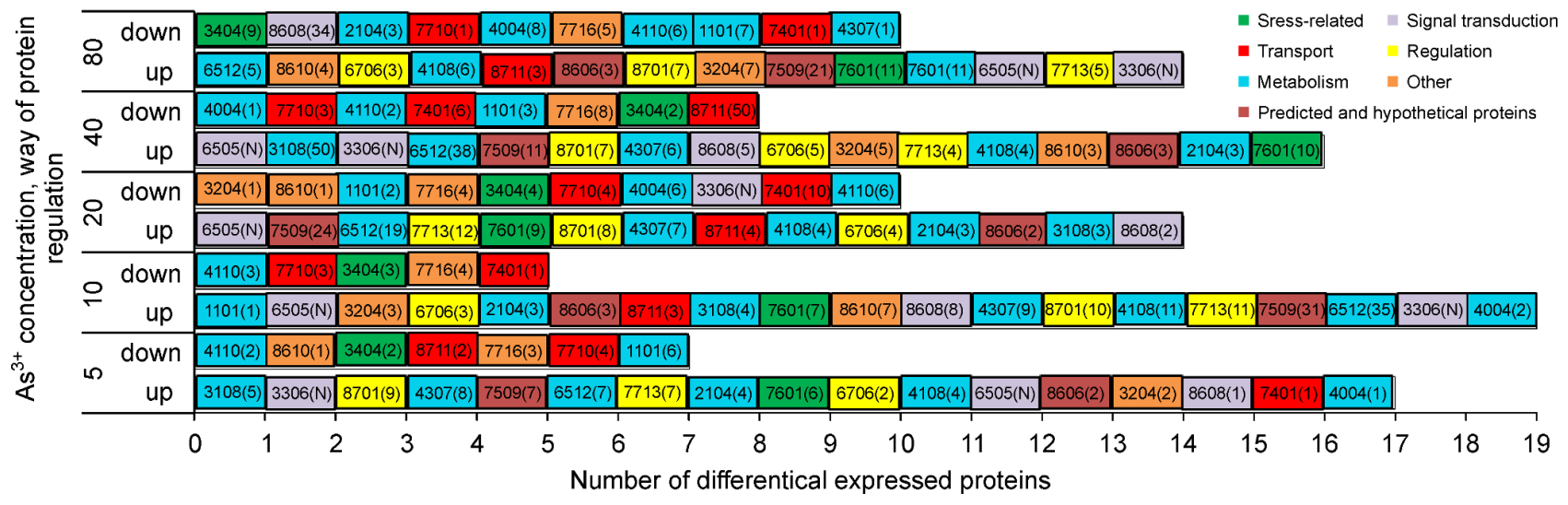

Fig. 3 Differentially expressed proteins in earthworm Eisenia fetida exposed to $\mathrm{As}^{3+}$ at indicated concentrations for 60 days. Each cell represents one protein. Number in cell is Match ID in PDQuestTM Basic- 8.0.1 2-DE Analysis Software (also shown in Table 1). Number in parentheses is fold up-regulation or down-regulation compared with control. $\mathrm{N}$ represent the new occurrence protein. Different colors represent different functional groups of proteins.

A

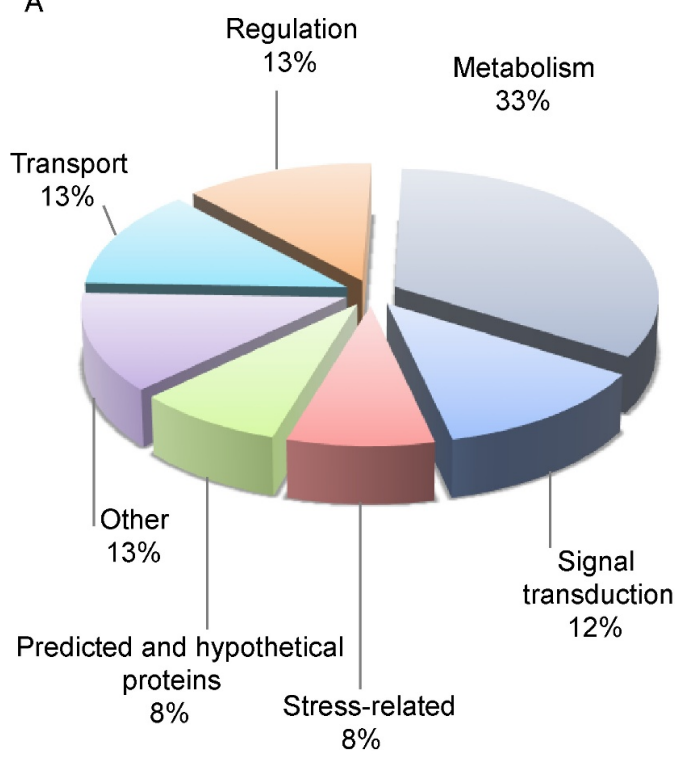

B

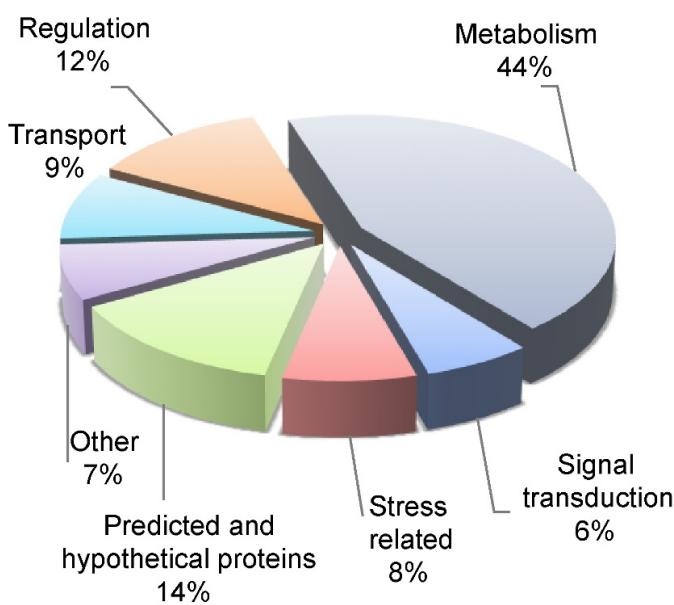

Fig. 4 Proportions of different functional groups of differentially expressed proteins from earthworms exposed to arsenite. (A) by number; (B) by fold change.

\subsubsection{Stress-related}

The spot 7601(HSPA8) was identified as heat shock protein (HSP). The HSPs are a kind of heat stress protein, they widely exist in bacteria and mammals. Usually the HSPs are not expressed until the cells are stimulated externally such as heavy metals, heat, salinity, and oxidative stress (Cara et al., 2005). In this experiment, spot 7601 was upregulated in all the As treated groups. The expression of the spot 7601 increased with the As concentration increased, the maximum of the fold change times reached 10.7 in the $80 \mathrm{mg} \mathrm{kg}^{-1}$ group. In the PPI (Fig. 5), it was correlated with three other spots. This result was similar to the earthworm exposure to enrofloxacin (Lu et al., 2018) and human lung cells to arsenite (Lau et al., 2004), whereby this protein was upregulated in response to exposure to the two chemicals, interestingly HSP70 was downregulated in earthworm under $\mathrm{Cd}$ exposure (Zhang et al., 2017), suggesting that maybe the mechanisms employed in response to different heavy metals is varied.

Lumbricine kinase (spot 3404, CKB) has an important activity in ATP binding. This protein has a crucial role in coupling energy production to energy utilization in the body (Ellington, 2001). In this study, the protein lumbricine kinase was downregulated in all the As treatments, while in other 


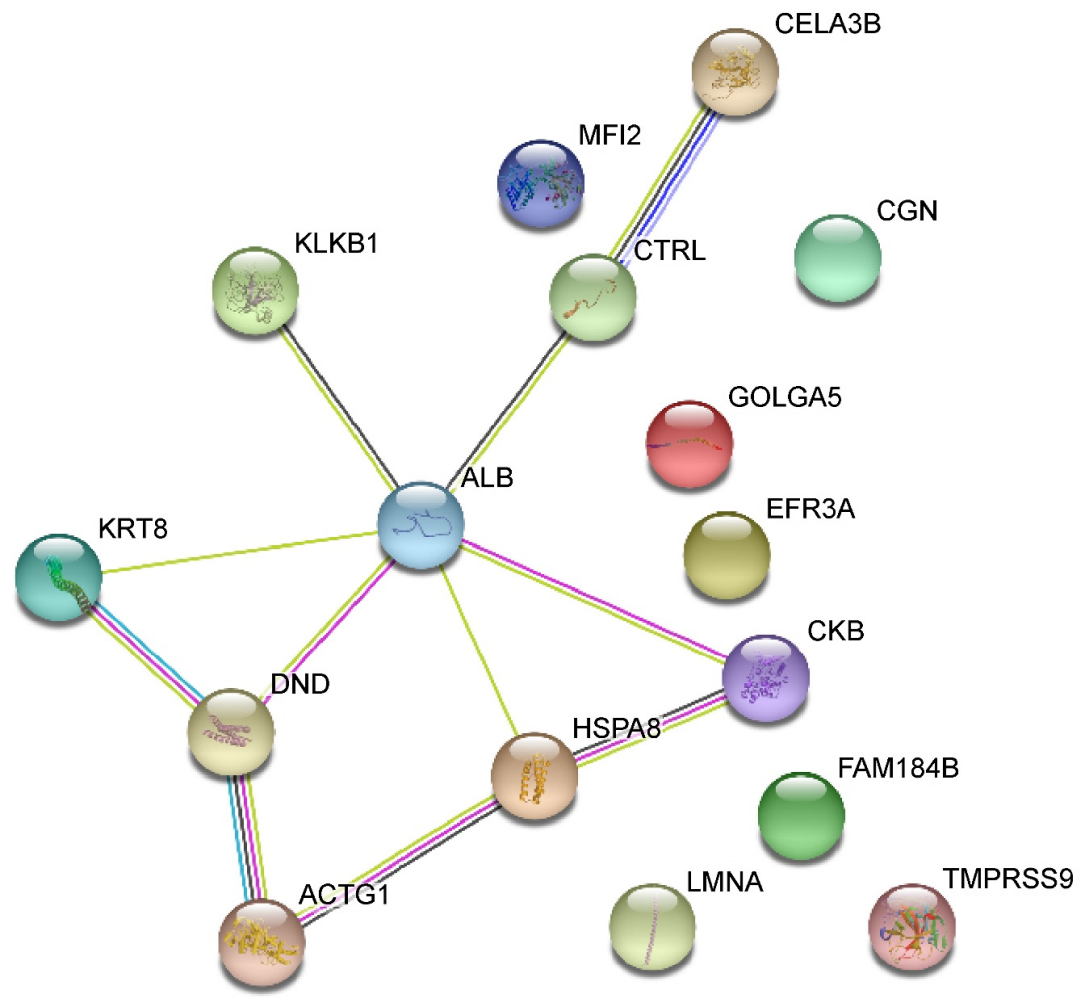

Fig. 5 Protein-protein interaction analysis of significantly differentially expressed proteins. Icon in each circle indicates three-dimensional structure of proteins. No icon indicates that there was no information on protein structure in STRING database. Size and color of circle do not indicate strength of interaction (size was adjusted to accommodate 3D structure of the protein). Colored lines indicate types of evidence for interactions between proteins, as follows: known interaction from curated database (light blue line) or experimental evidence (magenta line); predicted interaction based on gene fusion (red line), gene neighborhood (green line), or gene co-occurrence (blue line); and other lines of evidence, text mining (yellow line), co-expression (black line), or homology (light blue line).

studies such as Escherichia coli 0157:H7 (Wang et al., 2010a) to cadmium stress, this protein was upregulated. These results are different to this study. In this study, the expression of spot 3404 decreased with the increasing As concentration except in the $40 \mathrm{mg} \mathrm{kg}^{-1}$ group. The minimum was in the $80 \mathrm{mg} \mathrm{kg}^{-1}$ group, here the fold change reached 9.4. The reason might be that the different pollutants cause different responses. The process is very complicated in the body. The mechanism is not clear until now.

\subsubsection{Transport}

Spot 7710 (MFI2) was similar to the transferrin in the tobacco hornworm. Transferrin is an iron carrier protein in serum. The iron can be transported into the cell via receptor-mediated endocytosis (Andrews and Schmidt, 2007). This protein is an iron binding transport protein which binds the $\mathrm{Fe}^{3+}$ ion in association with the binding of an anion. Transferrin is required for cell survival and growth, and this protein transferrin as well as L-glutamine, were identified as crucial regulators of ferroptosis, they can induce the life-essential protein cytochrome $c$ pro-death in the intrinsic apoptotic pathway (Gao et al., 2015). This protein was downregulated in all the As treated groups, the maximum fold change reached 4.35 under the $20 \mathrm{mg} \mathrm{kg}^{-1}$ group, while the minimum was in the $80 \mathrm{mg} \mathrm{kg}^{-1}$ group, the fold change time is 1.29 . With transferrin downregulated, it is possible that the iron cannot be loaded to the cell and thus the earthworms' growth may be influenced, this result can be seen in the Table S1.

Spot 8711 (GOLGA5) was similar to the golgin subfamily $A$ member 5 OS in mouse. The GOLGA5 is involved in maintaining Golgi structure, and this protein stimulates the formation of Golgi stacks and ribbons. This protein was upregulated in all the As treated groups except the $5 \mathrm{mg} \mathrm{kg}^{-1}$ group and $40 \mathrm{mg} \mathrm{kg}^{-1}$ group. The expression of spot 8711 was different in the different As concentration, the maximum fold change reached 20.4 under the $40 \mathrm{mg} \mathrm{kg}^{-1}$ group. These two proteins have no interactions with the other proteins in Fig. 5.

Spot 7401 (ALB) was identified as serum albumin in the golden hamster. Serum albumin is the main components of the plasma and the protein has good binding ability to water, $\mathrm{Ca}^{2+}, \mathrm{Na}^{+}, \mathrm{K}^{+}$, fatty acids, hormones, bilirubin and drugs. The amount of the serum albumins in the circulatory system is very much. Serum albumins is abundant in the circulatory system 
and mainly participate in binding and transporting endogenous and exogenous ligands (Zolese et al., 2000). Serum albumin can enhance the apparent solubility of hydrophobic drugs in plasma and modulate their delivery, disposition, efficacy and distribution to cells in vivo and in vitro (Xu et al., 2008; Chaturvedi et al., 2015). Serum albumin is the major zinc transporter in plasma, typically binding about $80 \%$ of all plasma zinc. This protein was downregulated in all the As treated groups except the $5 \mathrm{mg} \mathrm{kg}^{-1}$ group. The maximum fold change reached 9.9 in the $20 \mathrm{mg} \mathrm{kg}^{-1}$ group. The highest expression was found in the $5 \mathrm{mg} \mathrm{kg}^{-1}$ group. It was upregulated compared to the control group. The fold change time is 1.2. It was associated with six proteins spots (CTRL, KLKB1, KRT8, DMD, HSPA8 and CKB).

\subsubsection{Regulation}

Spot 7713 (EFR3A) is similar to the protein EFR3 homolog in Caenorhabditis elegans, which is the component of a complex required to localize phosphatidylinositol 4-kinase $(\mathrm{P} / 4 \mathrm{~K})$ to the plasma membrane. This protein is involved in the maintenance and structural degeneration of sensory and motor nervous tissue. The EFR3A was upregulated in all the As treated groups, the maximum fold change was 12.2 in the 20 $\mathrm{mg} \mathrm{kg}^{-1}$ As group, the minimum was 4.3 in the $40 \mathrm{mg} \mathrm{kg}^{-1}$ group.

Spot 8701 (FAM184B) showed similarity to a human protein, FAM184B. This protein is involved in the interaction between the microtubules and chromatin. Information on FAM184B is limited, one paper reported that variants within the FAM184B gene were associated with feed intake in cattle (Lindholm-Perry et al., 2011). This protein was upregulated in all the As treated groups. The expression of spot 8701 reached maximum in the $10 \mathrm{mg} \mathrm{kg}^{-1}$ group. The minimum was in the $80 \mathrm{mg} \mathrm{kg}^{-1}$ group. This may suggest that As induced the FAM184B gene.

Spot 6706 (CGN) was similar to the cingulin in Sorex araneus, this protein plays an important role in the formation and regulation of the tight junction paracellular permeability barrier. The protein CGN was upregulated in all the As treated groups. The expression of the spot 6706 increased with the As concentration except in the $80 \mathrm{mg} \mathrm{kg}^{-1}$ group. The highest was in the $40 \mathrm{mg} \mathrm{kg}^{-1}$ group. The fold change reached 5.0, while the lowest was in the $5 \mathrm{mg} \mathrm{kg}^{-1}$ group.

\subsubsection{Other}

Spot 7716 (DMD) was identified as dystrophin, and it was associated with three other spots. DMD anchors the extracellular matrix to the cytoskeleton via F-action and DMD is a ligand for dystroglycan. It is reported that the DMD is the component of the dystrophin-associated glycoprotein complex found around the synapses in the nervous system and the neuromuscular junction. The synapses are an important part of information transmission. In the mid-1800s, DMD was first described (Meryon, 1852). This protein usually found on the cytoplasmic surface of skeletal muscle cell membranes. The protein is absent in Duchenne muscular dystrophy as well as mdx (X-linked muscular dystrophy) (Bernier et al., 1995). DMD protects the sarcolemma during muscle contraction (Petrof et al., 1993). DMD plays an important role in myofiber integrity, mainly by interactions with $\beta$-dystroglycan and other members of the transmembrane dystrophin-associated protein complex (Vulin et al., 2014). In this study, this protein was downregulated in all the As treated groups, the maximum fold change reached 7.71 .

Spot 8610 (KRT8) showed similarity to keratin, type II cytoskeletal 8 in rat. The combination of KRT8 and KRT19 plays an role in linking the contractile apparatus to dystrophin. This protein was upregulated in the $10,40,80 \mathrm{mg} \mathrm{kg}^{-1}$ As treated groups, the maximum fold change reached 7.1 in the $10 \mathrm{mg} \mathrm{kg}^{-1}$ group, suggesting that the arsenite may enhance this protein expression.

Spot 3204 (TMPRSS9) was upregulated in all the As treatments except the $20 \mathrm{mg} \mathrm{kg}^{-1}$ group, and the highest was in the $80 \mathrm{mg} \mathrm{kg}^{-1}$ group, fold change reached 7.3. This protein was identified as a lumbrokinase-3 precursor in the database. This protein can degrade the fibrinogen in the blood. This may be related to the formation of the blood clots (Lu et al., 2018). This result was like those found in earthworms exposed to enrofloxacin (Lu et al., 2018). This may be indicative that this protein is particularly affected by exposure to hazardous materials in the earthworm.

\subsubsection{Predicted and hypothetical proteins}

Because the data of the earthworms in the database is limited, spots 7509 and 8606 cannot be found in the database, and they were looked as predicted and hypothetical proteins. They were labeled as ACTG1 and LMNA in Fig. 5, respectively. The two spots were upregulated in all the As treated groups. The maximum change fold of the spot 7509 reached 31 in the 10 $\mathrm{mg} \mathrm{kg}^{-1}$ group, while the spot 8606 is 3 under $10 \mathrm{mg} \mathrm{kg}^{-1}$ group.

\subsection{Validation of differentially expressed proteins}

Western blots were conducted to verify the results of mass spectrometry for six proteins. The expression of BSA (spot 7401) was different compared to the proteomic results, BSA was significantly downregulated in the 20 and $40 \mathrm{mg} \mathrm{kg}^{-1} \mathrm{As}$ groups, but in the western blot the results showed that this protein was only significantly downregulated in the $80 \mathrm{mg} \mathrm{kg}^{-1}$ group. The CD71 (spot 7710) expression by western blot was similar to the results by $2-\mathrm{DE}$, the protein was significantly downregulated in all the As treated groups, in the 2-DE, the 5 and $20 \mathrm{mg} \mathrm{kg}^{-1}$ groups were the minimum, but in the western blot results, the minimum was the $5 \mathrm{mg} \mathrm{kg}^{-1}$ group. The cingulin (spot 6706) expression by western blot was also different compared to the 2-DE results. They were significantly upregulated in all the As treated groups, but in the western blot 
results, the cingulin was significant upregulated only in the 40 $\mathrm{mg} \mathrm{kg}^{-1}$ group. The expressions of CK8 (spot 8610), DMD (spot 7716) and HSP70 (spot 7601) were similar to the 2-DE results. DMD was significantly downregulated in all the As treated groups. HSP70 was upregulated in all the As treated groups. Generally, western blot results were in concordance with the proteomic analyses.

3.5 Protein-protein interactions of the different expressed proteins

We can see the interactions of the DEPs in Fig. 5. The protein-protein interactions (PPI) networks were constructed according to the STRING database. Different color lines indicate types of evidence for interactions between proteins. Usually, the more line present, the greater important the protein. So, in this study, ALB is the most important protein. ALB was identified as serum albumin, regarded as the major lipid binding protein in plasma (Guo et al., 2009). It is the most abundant carrier protein in blood plasma and plays an important role in determining the absorption, distribution, metabolism and excretion of drugs. ALB was related to 6 other proteins (KLKB1, KRT8, DMD, HSPA8, CK8 and CTRL), followed by DMD and HSPA8 (related to three other proteins). There were also relationships among CELA3B, CTRL, KLKB1, KRT8, DMD, ACTG1, CKB, HSPA8 and ALB. The remaining proteins acted independently. In this study, $\mathrm{As}^{3+}$ influenced the metabolism, stress-related proteins, this result is like results published by Zhang et al. (2020). The expression of the protein changed under different $\mathrm{As}^{3+}$ concentration (Zhang et al., 2020), the As influenced the liver of the rat, causing the damage of the liver, containing oxidative stress, apoptosis, and inflammation.

\section{Conclusion}

As we know, this is the first toxicoproteomic analysis of earthworm exposed to $\mathrm{As}^{3+}$. The exposure of $\mathrm{As}^{3+}$ significantly changes the expression of many functional proteins in earthworm. 36 DEPs were found in the gel maps and 24 of them were successfully identified. $79.2 \%$ of the DEPs were upregulated compared to the control group. The maximum fold change reached 53.8 in spot 3108 in the $80 \mathrm{mg} \mathrm{kg}^{-1}$ As group. The mechanisms of $\mathrm{As}^{3+}$ toxicity involve metabolism, signal transduction, stress response, transport, and other cellular functions, and gives a starting point for further functional research. The protein-protein interaction between the DEPs indicated that ALB is very important, as it is related to 6 other proteins. Western blot results were in line with the proteomic analyses. This study implies that it is possible to develop techniques to detect heavy metal pollution in soil using earthworms. An important animal in terrestrial ecology, earthworms have potential to be an animal model for the assessment of heavy metal pollution and its environmental risk.

\section{Acknowledgments}

This research was supported by the Shanghai Agriculture Applied Technology Development Program of China (2021 No. 2-2), the Natural Science Projects of Henan University of Technology, China (No. 2019BS037), the Open Fund Project of State Environmental Protection Key Laboratory of Monitoring for Heavy Metal Pollutants (SKLMHM202106) and the National Natural Science Foundation of China (No. 41471203).

\section{Electronic supplementary material}

Supplementary material is available in the online version of this article at https://doi.org/10.1007/s42832-021-0126-y and is accessible for authorized users.

\section{References}

Akazawa, S.I., Tokuyama, H., Sato, S., Watanabe, T., Shida, Y., Ogasawara, W., 2018. High-pressure tolerance of earthworm fibrinolytic and digestive enzymes. Journal of Bioscience and Bioengineering 125, 155-159.

Andrews, N.C., Schmidt, P.J., 2007. Iron homeostasis. Annual Review of Physiology 69, 69-85.

Bernier, S.M., Utani, A., Sugiyama, S., Doi, T., Polistina, C., Yamada, Y., 1995. Cloning and expression of laminin Chain (M-Chain) in the mouse. Matrix Biology 14, 447-455.

Cara, J.B., Aluru, N., Moyano, F.J., Vijayan, M.M., 2005. Fooddeprivation induces HSP70 and HSP90 protein expression in larval gilthead sea bream and rainbow trout. Comparative Biochemistry and Physiology. Part B, Biochemistry and Molecular Biology 142, 426-431.

Chaturvedi, S.K., Ahmad, E., Khan, J.M., Alam, P., Ishtikhar, M., Khan, R.H., 2015. Elucidating the interaction of limonene with bovine serum albumin: a multi-technique approach. Molecular BioSystems 11, 307-316.

Ciryam, P., Tartaglia, G.G., Morimoto, R.I., Dobson, C.M., Vendruscolo, M., 2013. Widespread aggregation and neurodegenerative diseases are associated with supersaturated proteins. Cell Reports 5, 781-790.

Daware, V., Kesavan, S., Patil, R., Natu, A., Kumar, A., Kulkarni, M., Gade, W., 2012. Effects of arsenite stress on growth and proteome of Klebsiella pneumoniae. Journal of Biotechnology 158, 8-16.

Ellington, W.R., 2001. Evolution and physiological roles of phosphagen systems. Annual Review of Physiology 63, 289-325.

Fanous, A., Weiss, W., Gorg, A., Jacob, F., Parlar, H., 2008. A proteome analysis of the cadmium and mercury response in Corynebacterium glutamicum. Proteomics 8, 4976- 4986.

Gao, M., Monian, P., Quadri, N., Ramasamy, R., Jiang, X., 2015. Glutaminolysis and transferrin regulate ferroptosis. Molecular Cell 59, 298-308.

Ge, T., Lang, G., 2003. Research progress of earthworm kinase. Journal of Biotechnology 100, 48-52.

Gong, P., Perkins, E.J., 2016. Earthworm toxicogenomics: A renewed genome-wide quest for novel biomarkers and mechanistic 
insights. Applied Soil Ecology 104, 12-24.

Guo, R., Ding, X., Xiong, W., Zhong, X., Liang, W., Gao, S., Hong, M., Sun, Y., 2015. Earthworms as agents for ecotoxicity in roxarsonecontaminated soil ecosystem: a modeling study of ultrastructure and proteomics. Environmental Science and Pollution Research International 22, 12435-12449.

Guo, S.H., Shi, X.L., Yang, F., Chen, L.Q., Meehan, E.J., Bian, C.B., Huang, M.D., 2009. Structural basis of transport of lysophospholipids by human serum albumin. Biochemical Journal 423 , 23-30.

Huang, R.Q., Gao, S.F., Wang, W.L., Staunton, S., Wang, G., 2006. Soil arsenic availability and the transfer of soil arsenic to crops in suburban areas in Fujian Province, southeast China. Science of the Total Environment 368, 531-541.

Ji, C., Wu, H., Wei, L., Zhao, J., Lu, H., Yu, J., 2013. Proteomic and metabolomic analysis of earthworm Eisenia fetida exposed to different concentrations of 2,2',4,4'-tetrabromodiphenyl ether. Journal of Proteomics 91, 405-416.

Katagiri, F., Hara, T., Yamada, Y., Urushibata, S., Hozumi, K., Kikkawa, Y., Nomizu, M., 2014. Biological activities of the homologous loop regions in the laminin alpha chain LG modules. Biochemistry 53, 3699-3708.

Kwon, J.C., Lee, J.S., Jung, M.C., 2012. Arsenic contamination in agricultural soils surrounding mining sites in relation to geology and mineralization types. Applied Geochemistry 27, 1020-1026.

Lau, A.T.Y., He, Q.Y., Chiu, J.F., 2004. A proteome analysis of the arsenite response in cultured lung cells evidence for in vitro oxidative stress-induced apoptosis. Biochemical Journal 382 , 641-650.

Li, Y., Tang, H., Hu, Y., Wang, X., Ai, X., Tang, L., Matthew, C., Cavanagh, J., Qiu, J., 2016. Enrofloxacin at environmentally relevant concentrations enhances uptake and toxicity of cadmium in the earthworm Eisenia fetida in farm soils. Journal of Hazardous Materials 308, 312-320.

Lindholm-Perry, A.K., Sexten, A.K., Kuehn, L.A., Smith, T.P., King, D. A., Shackelford, S.D., Wheeler, T.L., Ferrell, C.L., Jenkins, T.G., Snelling, W.M., Freetly, H.C., 2011. Association, effects and validation of polymorphisms within the NCAPG- LCORL locus located on BTA6 with feed intake, gain, meat and carcass traits in beef cattle. BMC Genetics 12, 1-13.

Liu, C.P., Luo, C.L., Gao, Y., Li, F.B., Lin, L.W., Wu, C.A., Li, X.D., 2010. Arsenic contamination and potential health risk implications at an abandoned tungsten mine, southern China. Environmental Pollution 158, 820-826.

Lu, X., Li, Y., Thunders, M., Matthew, C., Wang, X., Ai, X., Zhou, X., Qu, J., 2018. Effect of enrofloxacin on the proteome of earthworms. Science of the Total Environment 616-617, 531-542.

Mandal, B.K., Suzuki, K.T., 2002. Arsenic round the world: a review. Talanta 58, 201-235.

Meryon, E., 1852. On granular and fatty degeneration of the voluntary muscles. Medico-Chirurgical Transactions 35, 73-85.

Mihara, H., Akazawa, T., 1983. Fibrinolotic enzyme extracted from the earthworm. Thrombosis and Haemostasis 50, 258-263.

Mihara, H., Sumi, H., Yoneta, T., Mizumoto, H., Ikeda, R., Seiki, M., Maruyama, M., 1991. A novel fibrinolytic enzyme extracted from the earthworm, Lumbricus rubellus. Japanese Journal of Physiol- ogy 41, 461-472.

Naaby-Hansen, S., Waterfield, M.D., Cramer, R., 2001. Proteomics post-genomic cartography to understand gene function. Trends in Pharmacological Sciences 22, 376-384.

Ning, M., Wei, P., Shen, H., Wan, X., Jin, M., Li, X., Shi, H., Qiao, Y., Jiang, G., Gu, W., Wang, W., Wang, L., Meng, Q., 2019. Proteomic and metabolomic responses in hepatopancreas of whiteleg shrimp litopenaeus vannamei infected by microsporidian enterocytozoon hepatopenaei. Fish \& Shellfish Immunology 87, 534-545.

Oremland, R.S., Stolz, J.F., 2003. The ecology of arsenic. Science 300, 939-944.

Park, Y., Ryu, E., Kim, H., Jeong, J., Kim, J., Shim, J., Jeon, S., Jo, Y., Kim, W., Min, B., 1999. Characterization of antithrombotic activity of lumbrokinase-immobilized polyurethane valves in the total artificial heart. Artificial Organs 23, 210-214.

Pendergrass, A., Butcher, D.J., 2006. Uptake of lead and arsenic in food plants grown in contaminated soil from Barber Orchard, NC. Microchemical Journal 83, 14-16.

Petrof, B.J., Shrager, J.B., Stedman, H.H., Kelly, A.M., Sweeney, H.L., 1993. Dystrophin protects the sarcolemma from stresses developed during muscle contraction. Proceedings of the National Academy of Sciences of the United States of America 90, 37103714.

Ricketts, H.J., Morgan, A.J., Spurgeon, D.J., Kille, P., 2004. Measurement of annetocin gene expression: a new reproductive biomarker in earthworm ecotoxicology. Ecotoxicology and Environmental Safety $57,4-10$.

Sauve, S., Hendawi, M., Brousseau, P., Fournier, M., 2002. Phagocytic response of terrestrial and aquatic invertebrates following in vitro exposure to trace elements. Ecotoxicology and Environmental Safety 52, 21-29.

Shah, S., Damare, S.R., 2018. Differential protein expression in a marine-derived Staphylococcus sp. NIOSBK35 in response to arsenic (III). 3 Biotech 8, 287.

Szewczak-Harris, A., Löwe, J., 2017. Cryo-EM reconstruction of AlfA from Bacillus subtilis reveals the structure of a simplified actin-like filament at 3.4 A resolution. BioRxiv190744.

Tang, R., Lan, P., Ding, C., Wang, J., Zhang, T., Wang, X., 2020. A new perspective on the toxicity of arsenic-contaminated soil: Tandem mass tag proteomics and metabolomics in earthworms. Journal of Hazardous Materials 398, 122825.

Vulin, A., Wein, N., Strandjord, D.M., Johnson, E.K., Findlay, A.R., Maiti, B., Howard, M.T., Kaminoh, Y.J., Taylor, L.E., Simmons, T.R., Ray, W.C., Montanaro, F., Ervasti, J.M., Flanigan, K.M., 2014. The ZZ domain of dystrophin in DMD: making sense of missense mutations. Human Mutation 35, 257-264.

Wang, X., Chang, L., Sun, Z., Zhang, Y., 2010a. Comparative proteomic analysis of differentially expressed proteins in the earthworm Eisenia fetida during Escherichia coli O157_H7 stress. Journal of Proteome Research 9, 6547-6560.

Wang, X., Chang, L., Sun, Z., Zhang, Y., Yao, L., 2010b. Analysis of earthworm Eisenia fetida proteomes during cadmium exposure: An ecotoxicoproteomics approach. Proteomics 10, 4476-4490.

Wang, Y., Wu, Y., Cavanagh, J., Yiming, A., Wang, X., Gao, W., Matthew, C., Qiu, J., Li, Y., 2018. Toxicity of arsenite to earthworms 
and subsequent effects on soil properties. Soil Biology \& Biochemistry 117, 36- 47.

Wu, S., Li, J., Jin, X., 2018. iTRAQ-based quantitative proteomic analysis reveals important metabolic pathways for arsenic-induced liver fibrosis in rats. Scientific Reports 8, 3267.

Wu, S., Zhao, S., Shen, F., Xu, M., 2013. Establishment and optimization of two dimensional electrophoresis technology system for earthworm proteome. Journal of Zhejiang University of Technology 41, 156-160.

Xu, H., Liu, Q., Zuo, Y., Bi, Y., Gao, S., 2008. Spectroscopic studies on the interaction of vitamin $C$ with bovine serum albumin. Journal of Solution Chemistry 38, 15-25.

Yang, J., Pan, W., Sun, X., Zhao, X., Yuan, G., Sun, Q., Huang, J., Zhu, X., 2015. Immunoproteomic profile of Trichinella spiralis adult worm proteins recognized by early infection sera. Parasites \& Vectors 8, 20.

Ye, J.S., Liu, J., Ou, H.S., Wang, L.L., 2016. Degradation of ciprofloxacin by $280 \mathrm{~nm}$ ultraviolet-activated persulfate: Degradation pathway and intermediate impact on proteome of Escherichia coli. Chemosphere 165, 311-319.

Zhang, L., Duan, X., He, N., Chen, X., Shi, J., Li, W., Xu, L., Li, H., 2017. Exposure to lethal levels of benzo[a]pyrene or cadmium trigger distinct protein expression patterns in earthworms (Eisenia fetida). Science of the Total Environment 595, 733-742.

Zhang, Z.G., Guo, C.M., Jiang, H.J., Han, B., Wang, X.Q., Li, S.Y., Lv, Y.Y., Lv, Z.J., Zhu, Y., 2020. Inflammation response after the cessation of chronic arsenic exposure and post-treatment of natural astaxanthin in liver: potential role of cytokine-mediated cellcell interactions. Food \& Function 11, 9252-9262.

Zolese, G., Falcioni, G., Bertoli, E., Galeazzi, R., Wozniak, M., Wypych, Z., Gratton, E., Ambrosini, A., 2000. Steady-state and time resolved fluorescence of albuminsInteracting with $\mathrm{N}$-Oleylethanolamine, a component of the endogenous N-Acylethanolamines. Proteins 40, 39-48. 